\title{
Selection of Pinus pinea L. plus tree candidates for cone production
}

\author{
Isabel CARRASQUINHO ${ }^{1 *}$, João FREIRE ${ }^{2}$, Abel RodRIGUES $^{1}$, Margarida TOMÉ $^{2}$ \\ ${ }^{1}$ Instituto Nacional dos Recursos Biológicos, L-INIA, Quinta do Marquês, 2780-159 Oeiras, Portugal \\ ${ }^{2}$ Instituto Superior de Agronomia, Universidade Técnica de Lisboa, Tapada da Ajuda, 1349-017 Lisboa, Portugal
}

(Received 19 August 2009; accepted 27 February 2010)

\author{
Keywords: \\ Pinus pinea L. / \\ discriminant analysis / \\ cluster analysis / \\ plus trees / \\ cone production
}

\begin{abstract}
- Multivariate statistical analysis was used to define different developmental stages for stone pine (Pinus pinea L.) considering tree size and cone production, without site-specific information.

- This was achieved in two steps. First, trees from permanent plots were classified using cluster analysis in five different stages. Second, discriminant analysis was applied to confirm the robustness of the groups generated by cluster analysis and to allow the assignment of new stone pine trees to one of the five development stages. Each development stage was associated with an average cone production.

- A methodology for selecting candidates for plus trees was suggested. Trees belonging to the 90th quartile or higher for the number of cones per crop and for cone crop weight were identified throughout the three years of the study.

- Trees were evaluated as potential candidates for plus trees using the following variables: the number of cones, cone crop weight and relative production capacity. The relative production capacity was defined as the cone crop weight per square meter of the crown area.
\end{abstract}

\section{INTRODUCTION}

In Portugal, stone pine (Pinus pinea L.) occupies approximately 118000 hectares (DGRF, 2006), which represents $3.5 \%$ of the total forest area. The total area devoted to stone pine has increased since the last inventory by about $51 \%$, which is due to an increased interest in the species by forest land owners. Stone pine is a valuable species and is used for kernel, resin and wood production. It can also be used as shelter belts and is often found in natural parks.

More than half of the cone production of stone pine comes from the southern coastal area, where it has a high economic impact. Portuguese stone pine forest includes $74 \%$ mixed stands and 26\% pure stands (DGRF, 2006). Productive stands are often uneven-aged. Even-aged stands are typically younger because, since 1992, a part of the EU forest fund has been used to promote stone pine plantations.

Increasing kernel production, in terms of quantity and quality, is one of the main purposes of the Pinus pinea $\mathrm{L}$. improvement program (Barreira and Alpuim, 1988; Gordo, 2004). The selection of plus trees is the first step in improvement programs (Zobel and Talbert, 1984). Thus far, 64 plus trees have been phenotypically selected in Portugal. Cone crop production, assessed through the number of cones produced, was the

* Corresponding author: icarrasquinho@ netcabo.pt criterion for selecting plus trees. Cone crop weight should also be used as a criterion for tree selection, considering the empirical cone crop production cycle. Long-term empirical evidence has shown that cone yield follows a cycle of 7 to 8 years. In fact, according to Carneiro (2005), the number of cones and cone crop weight can be used as a proxy for pine nut production in Pinus pinea L. This author reported a high genetic correlation between cone weight and seed weight per cone $\left(r_{g}=0.86\right)$, kernel weight and the weight of a hundred seeds $\left(r_{g}=0.97\right)$, and kernel length and the weight of a hundred seeds $\left(r_{g}=0.93\right)$. Cone crop weight and the number of cones are preferable criteria from an operational standpoint when compared with kernel traits.

The 64 selected plus trees are typically the oldest among all the trees in the stands. To assure the sustainability of the breeding program, selection should be extended to younger and/or smaller trees, which must also be the most productive for their age and size. The identification of different developmental groups, accomplished by gathering trees with similar dimensions and cone production, is a way to guarantee unbiased plus tree selection, especially in uneven-aged stands. Cluster analysis and discriminant analysis are two popular statistical tools in the field of pattern recognition. The former method is an exploratory tool to find groups of datasets with similar characteristics and the latter method assigns a new item to its proper place in an established set of categories (Huang et al., 2007). 
In this context, the objectives of this study include:

(1) The definition of developmental stages for stone pine that occur in the provenance region $\mathrm{V}$ according to biometric characteristics and analyzing their relationship to cone production.

(2) The establishment of a methodology for classifying trees at different development stages using available dendrometrical and stand variables.

(3) The proposal of a methodology to aid in the selection of plus trees and to be included in the Pinus pinea L. improvement program for nut production.

\section{MATERIALS AND METHODS}

\subsection{Field data collection}

Data were obtained from 62 stone pine permanent plots established in stands representative of the different types that occur in the provenance region V (Cardoso and Lobo, 2001). The criteria for stand selection included composition (pure and mixed), structure (even-aged and uneven-aged) and type of regeneration (natural or out-planting). In the case of mixed stands, information about the dominant species (cork oak, maritime pine and stone pine) was also considered. This selection was implemented by the Portuguese Forest Services in cooperation with local associations of forest owners. The selected plots contained 1237 stone pines.

Diameter at breast height $(d)$, total height $(h)$, crown diameter $(c w)$ and crown height $(c l)$ were measured for all trees in each plot. Basal area $(g)$, crown area $(c a)$ and height to diameter ratio $(r h d)$ were computed from measured variables. Stand information such as the total number of trees $(N)$ and the total number of stone pine trees $(N P m)$ was also included in this study. Individual cone production was determined during three consecutive years and includes 2004/2005, 2005/2006 and 2006/2007. Cone production was determined by collecting, counting and weighing the cones from the trees. In the first year, five sample trees were evaluated in each plot but in the following two years all the trees were studied. Cone production per year was evaluated according to the number of cones and to the fresh cone crop weight, $n c_{t}$ and $w c_{t}$, respectively, where $t$ represents the harvesting year. These two traits are considered complementary for the evaluation of cone crop production (Carneiro, 2005). Relative production capacity for the $j$ th tree and the year $t\left(p c_{j t}\right)$ was computed according to the following formula:

$$
p c_{j t}=\frac{w c_{j t}}{c a_{j}} .
$$

\subsection{Data analysis}

Cluster analysis was used to identify tree groups with similar biometric characteristics. Once a tree cluster group was obtained, predictive discriminant analysis was applied to test the robustness of the groups generated by the cluster analysis and to establish a classification scheme that new units could be submitted to (Huberty, 1994).

The cluster profiles were also compared considering a set of variables related to cone productivity and to stand density. These variables, not included in the clustering process, were the number of cones $\left(n c_{1}, n c_{2}, n c_{3}\right)$ and cone crop weight $\left(w c_{1}, w c_{2}, w c_{3}\right)$ for the three years, the total number of trees per hectare $(N T)$ and the total number of stone pine trees per hectare $(N P m)$. A cluster was considered to be productive when the mean of the number of cones was greater than 40 cones per tree.

\subsubsection{Cluster analysis}

Cluster analysis was carried out to classify the 1237 pine trees into homogeneous groups according to their growth development. The basis variables used for the clustering process included diameter at breast height $(d)$, crown height $(c l)$, crown diameter $(c w)$, crown area $(c a)$, basal area $(g)$ and height diameter ratio $(r h d)$.

Standardized data were submitted to nonhierarchical cluster analysis using the FASTCLUS procedure from the SAS System program (SAS Institute Inc., 1999). The clustering process was accomplished by an iterative approach. Cluster results were evaluated using the root mean square standard deviation $(R M S)$, the distance to the nearest cluster and distance ratio $(D R)$ as statistical criteria. $R S M$ measures the average distance between the members within each cluster. The distance to the nearest cluster provides a measurement of the distance between cluster centroids. The distance ratio was obtained by dividing the distance to the nearest cluster by the $R M S$. This ratio indicates how well the clusters are separated (Thompson, 1999).

For each basis variable, the least squares means (LSMeans), standard errors (se) and significant differences between clusters were evaluated using the MIXED procedure of SAS. Annual cone production was also compared between clusters.

\subsubsection{Discriminant analysis}

Fisher's discriminant function was applied using the DISCRIM procedure in SAS. The performance of this analysis was evaluated by estimating the misclassification and hit rates, considering equal prior probabilities. The cross-validation approach was applied to reduce bias in the estimation of error rates. The response variables used for discriminant analysis were height to diameter ratio $(r h d)$, basal area $(g)$ and crown area $(c a)$. These variables were selected because they express not only the size of the tree but also the effects of past and present competition, which jointly influence cone production. These variables are easy to obtain in future tree classification.

\subsubsection{Selection of highly productive trees}

For each productive cluster $(c)$ and harvesting year $(t)$, trees $(j)$ were evaluated by their cone production, using the 


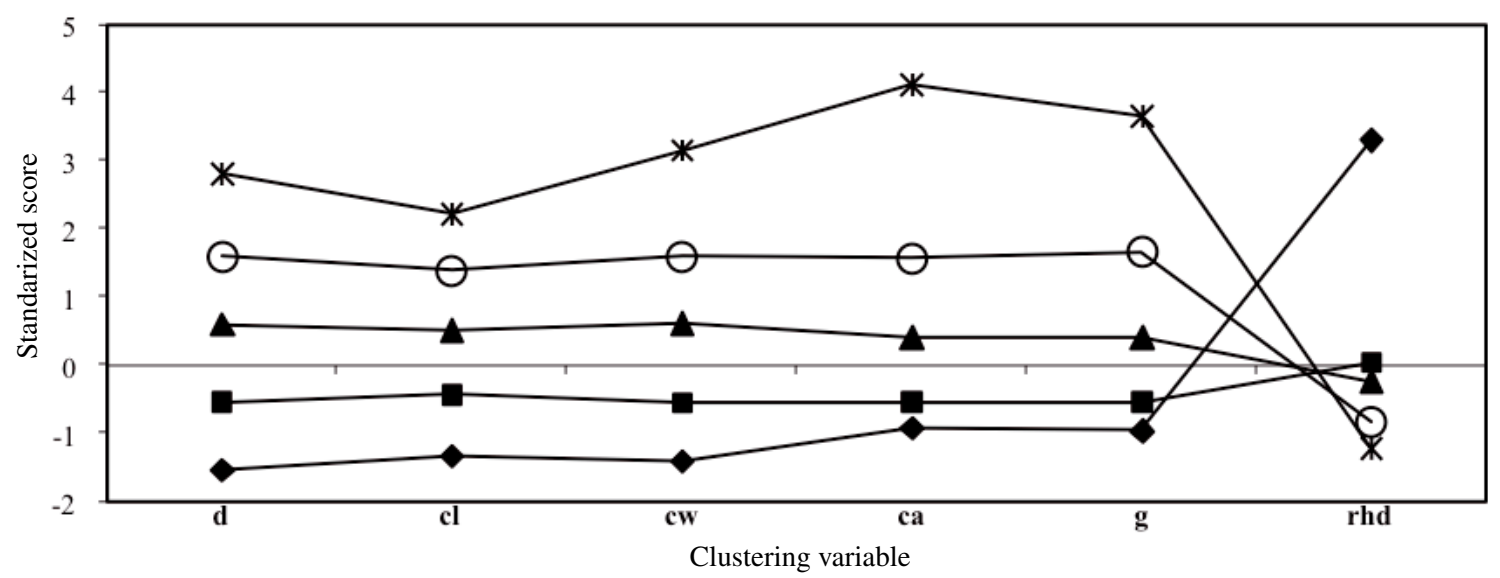

$\multimap$ cluster $1 \rightarrow$ cluster $2 \rightarrow$ cluster $3 \rightarrow$ cluster $4 \rightarrow$ cluster 5

Figure 1. Diagram showing the five clusters, 1, 2, 3, 4 and 5, which consider six standardized basis variables: diameter at breast height $(d)$, crown height $(c l)$, crown diameter $(c w)$, crown area $(c a)$, basal area $(g)$ and height diameter ratio $(r h d)$.

Table I. Least squares means (LS-Means) and standard error ( $s e$ ) of the basis clustering variables for each of the five clusters: diameter at breast height $(d)$, crown height $(c l)$, crown diameter $(c w)$, crown area $(c a)$, basal area $(g)$ and height diameter ratio $(r h d)$.

\begin{tabular}{ccccccc}
\hline Cluster ID & $d(\mathrm{~cm})$ & $c l(\mathrm{~m})$ & $c w(\mathrm{~m})$ & $c a\left(\mathrm{~m}^{2}\right)$ & $g\left(\mathrm{~m}^{2}\right)$ & $r h d$ \\
\hline 1 & $11.18(0.98) \mathrm{a}$ & $3.11(0.49) \mathrm{a}$ & $2.97(0.19) \mathrm{a}$ & $8.33(2.76) \mathrm{a}$ & $0.02(0.05) \mathrm{a}$ & $3.31(0.06) \mathrm{a}$ \\
2 & $27.89(0.27) \mathrm{b}$ & $5.00(0.14) \mathrm{b}$ & $6.22(0.05) \mathrm{b}$ & $31.8(0.76) \mathrm{b}$ & $0.07(0.01) \mathrm{a}$ & $1.63(0.02) \mathrm{b}$ \\
3 & $46.15(0.44) \mathrm{c}$ & $6.99(0.23) \mathrm{c}$ & $10.56(0.09) \mathrm{c}$ & $88.96(1.26) \mathrm{c}$ & $0.17(0.21) \mathrm{b}$ & $1.5(0.03) \mathrm{c}$ \\
4 & $62.42(0.61) \mathrm{d}$ & $9.70(0.31) \mathrm{d}$ & $14.12(0.12) \mathrm{d}$ & $159.4(1.72) \mathrm{d}$ & $0.39(0.28) \mathrm{c}$ & $1.26(0.04) \mathrm{d}$ \\
5 & $82.37(1.43) \mathrm{e}$ & $10.61(0.72) \mathrm{d}$ & $19.99(0.28) \mathrm{e}$ & $316.27(4.06) \mathrm{e}$ & $0.54(0.07) \mathrm{d}$ & $0.98(0.09) \mathrm{e}$ \\
\hline
\end{tabular}

Different letters (a, b, c, d and e) within the columns indicate significant differences at $p<0.05$ between clusters.

Table II. Cluster summary information: frequency, root mean square standard deviation $(R M S)$, distance to the nearest cluster and distance ratio.

\begin{tabular}{ccccc}
\hline Cluster ID & Number of trees & $R M S$ standard deviation & Distance to nearest cluster & Distance ratio \\
\hline 1 & 56 & 0.70 & 3.69 & 5.27 \\
2 & 741 & 0.43 & 2.30 & 5.35 \\
3 & 269 & 0.48 & 2.30 & 4.79 \\
4 & 145 & 0.58 & 2.46 & 4.24 \\
5 & 26 & 0.67 & 3.90 & 5.82 \\
\hline
\end{tabular}

following variables: the number of cones $\left(n c_{j c 1}, n c_{j c 2}, n c_{j c 3}\right)$, cone crop weight $\left(w c_{j c 1}, w c_{j c 2}, w c_{j c 3}\right)$ and relative productive capacity $\left(p c_{j c 1}, p c_{j c 2}, p c_{j c 3}\right)$. For each of the productive clusters, stone pine trees were given plus tree candidate status if they belonged to the 90th quartile for at least two out of the first six variables $\left(n c_{j c 1}, n c_{j c 2}, n c_{j c 3}, w c_{j c 1}, w c_{j c 2}, w c_{j c 3}\right)$. The relative productivity capacity was used for choosing the most productive tree out of the potential candidates. If more than one tree was identified in a permanent plot then the selection was based on the smallest tree with the highest productivity capacity, taking into account the years of evaluation. In each plot, only one tree was selected.

\section{RESULTS}

\subsection{Stone pine development stages}

According to the statistical criteria and the practical interpretation of cluster results, the best tree segmentation was obtained when the 1237 observations were assigned into five clusters. Figure 1 and Table I show that the five clusters were well separated according to the six standardized variables. The number of trees assigned to the different clusters varied between 26 and 741 (Tab. II). 
Table III. The least squares means (LS-Means) and standard error ( $s e$ ) of each of the five clusters for the variables associated with cone productivity: the number of cones $(n c)$, cone crop weight $(w c)$ and stand characteristics: total number of trees $(N T)$ and total number of stone pine trees $(N P m)$.

\begin{tabular}{ccccccccc}
\hline $\begin{array}{c}\text { Cluster } \\
\text { ID }\end{array}$ & $n c_{1}$ & $n c_{2}$ & $n c_{3}$ & $w c_{1}(\mathrm{~kg})$ & $w c_{2}(\mathrm{~kg})$ & $w c_{3}(\mathrm{~kg})$ & $N T$ & $N P m$ \\
\hline 1 & $1.62(45.30) \mathrm{a}$ & $0.86(6.00) \mathrm{a}$ & $2.47(9.01) \mathrm{a}$ & $0.5(14.43) \mathrm{a}$ & $0.14(1.23) \mathrm{a}$ & $0.55(2.47) \mathrm{a}$ & $146.46(8.42) \mathrm{a}$ & $122.59(6.69) \mathrm{a}$ \\
2 & $15.84(13.08) \mathrm{a}$ & $9.23(1.54) \mathrm{a}$ & $16.02(2.62) \mathrm{a}$ & $4.68(4.1) \mathrm{a}$ & $1.85(0.31) \mathrm{a}$ & $4.18(0.72) \mathrm{a}$ & $160.37(2.31) \mathrm{a}$ & $144.15(1.84) \mathrm{a}$ \\
3 & $94.99(13.58) \mathrm{b}$ & $50.3(2.98) \mathrm{b}$ & $60.11(4.06) \mathrm{b}$ & $30.11(4.33) \mathrm{b}$ & $10.3(0.61) \mathrm{b}$ & $16.11(1.14) \mathrm{b}$ & $107.65(3.84) \mathrm{b}$ & $76.67(3.05) \mathrm{b}$ \\
4 & $183.7(17.44) \mathrm{c}$ & $97.6(3.84) \mathrm{c}$ & $135.95(5.60) \mathrm{c}$ & $62.89(5.55) \mathrm{c}$ & $21.14(0.78) \mathrm{c}$ & $40.21(1.54) \mathrm{c}$ & $69.74(5.24) \mathrm{c}$ & $49.2(4.16) \mathrm{c}$ \\
5 & $603.65(31.07) \mathrm{d}$ & $266.06(9.44) \mathrm{d}$ & $365.38(12.88) \mathrm{d}$ & $165.59(9.90) \mathrm{d}$ & $54.56(1.93) \mathrm{d}$ & $107.96(3.52) \mathrm{d}$ & $48.02(12.36) \mathrm{c}$ & $35.5(9.82) \mathrm{c}$ \\
\hline
\end{tabular}

Different letters ( $\mathrm{a}, \mathrm{b}, \mathrm{c}$ and $\mathrm{d}$ ) within the columns indicate significant differences at $p<0.05$ between different clusters.

Table IV. Cross-validation of the five clusters, using the discriminant analysis method.

\begin{tabular}{|c|c|c|c|c|c|c|c|c|c|c|c|c|}
\hline \multirow{3}{*}{$\begin{array}{c}\text { Prior development } \\
\text { state } \\
\text { (cluster analysis) }\end{array}$} & \multicolumn{12}{|c|}{ Predicted development state (discriminant analysis) } \\
\hline & \multicolumn{2}{|c|}{ Cluster 1} & \multicolumn{2}{|c|}{ Cluster 2} & \multicolumn{2}{|c|}{ Cluster 3} & \multicolumn{2}{|c|}{ Cluster 4} & \multicolumn{2}{|c|}{ Cluster 5} & \multicolumn{2}{|c|}{ Total } \\
\hline & Number & $\%$ & Number & $\%$ & Number & $\%$ & Number & $\%$ & Number & $\%$ & Number & $\%$ \\
\hline Cluster 1 & 55 & 98.21 & 1 & 1.79 & 0 & 0 & 0 & 0 & 0 & 0 & 56 & 100 \\
\hline Cluster 2 & 3 & 0.54 & 726 & 97.98 & 12 & 1.62 & 0 & 0 & 0 & 0 & 741 & 100 \\
\hline Cluster 3 & 0 & 0 & 25 & 9.28 & 227 & 84.39 & 17 & 6.32 & 0 & 0 & 269 & 100 \\
\hline Cluster 4 & 0 & 0 & 0 & 0 & 19 & 13.10 & 124 & 85.52 & 2 & 1.38 & 145 & 100 \\
\hline Cluster 5 & 0 & 0 & 0 & 0 & 0 & 0 & 3 & 11.54 & 23 & 88.46 & 26 & 100 \\
\hline Total & 58 & 4.69 & 752 & 60.79 & 258 & 20.86 & 144 & 11.64 & 25 & 2.02 & 1237 & 100 \\
\hline
\end{tabular}

Column and row totals refer, respectively, to discriminant and cluster analysis.

The analysis of the statistics obtained (Tab. II) indicated that clusters 2 and 3 had a smaller RMS standard deviation. This means that the trees inside these two clusters were more similar to each other than to trees in other clusters. The distance to the nearest cluster indicated that segments 1 and 5 were isolated from the others. Nevertheless, segments 1, 2 and 5 , which had a higher magnitude of the distance ratio, were well-separated and consisted of homogeneous members.

The least squares means (LS-Means) for diameter at breast height $(d)$, crown diameter $(c w)$, crown area $(c a)$ and height diameter ratio $(r h d)$ were significantly different for the five clusters (Tab. I, Fig. 1). Trees included in clusters 1 to 5 were characterized by increasing size and by decreasing $\mathrm{rdh}$.

Table III provides a descriptive profile for the variables (LSMeans) related to cone productivity (number of cones and cone crop weight) and stand density in the five clusters. Clusters 1 to 5 were arranged according to increasing cone productivity and decreasing stand density. Clusters 3, 4 and 5 were significantly different with respect to cone productivity. These clusters were considered the productive clusters, as they included trees that produced more than 40 cones per crop. There was no evidence to suggest that clusters 1 and 2 were significantly different. Both of these clusters included trees that can be considered non-productive. This statement agrees with the observed tree dimensions because smaller trees do not produce cones, or produce fewer cones. Regarding stand density, there was also no evidence to distinguish cluster 1 from cluster 2 (higher densities) and cluster 4 from cluster 5 (lower densities).
The segmentation results obtained from the clustering variables were thereby supported by variables related to cone production and the stand, which were not included in the clustering process. Therefore, a classification into five developmental stages associated with both tree size and cone productivity can be defined as follows: juvenile (cluster 1), dominant vegetative growth (cluster 2), cone production phase I (cluster 3), cone production phase II (cluster 4) and cone production phase III (cluster 5). The last three are productive stages.

A mathematical method to test the significance of the five clusters is the application of discriminant analysis. The achieved hit rate of $90.91 \%$ (data not shown) was satisfactory and confirmed the previous classification developed by cluster analysis. Table IV compares the classification schemes obtained by both cluster and discriminant analysis. Clusters 1 , 2 and 5 are in agreement with the two classification schemes (98.21, 97.98 and $88.46 \%)$. The highest proportion of varying classification between analyses was observed in cluster 3 where 25 trees were allocated to cluster $2(9.28 \%)$ and 17 to cluster $4(6.32 \%)$. Despite the method or cluster under consideration, the percentage of well-ranked trees was higher than $84 \%$. This result shows that the three variables used in the discriminant analysis ( $c a, g$ and $r h d)$ are good indicators for the classification of stone pine by developmental stage.

Discriminant analysis also allowed us to define a classification scheme to be applied to new trees. Equations (2) to (6) are the Fisher's linear discriminant functions for each of the five developmental stages, from juvenile to cone production 
phase III:

juvenile stage:

$$
Y 1=-54.01+0.11 c a-27.89 g+32.44 r h d ;
$$

dominant vegetative growth stage:

$$
Y 2=-14.81+0.12 \mathrm{ca}-12.81 \mathrm{~g}+16.25 \mathrm{rhd}
$$

cone production phase I stage:

$$
Y 3=-22.31+0.26 c a-9.91 g+15.52 r h d ;
$$

cone production phase II stage:

$$
Y 4=-41.71+0.42 c a-4.36 g+13.34 r h d ;
$$

cone production phase III stage:

$$
Y 5=-134.68+0.81 c a+0.27 g+13.68 r h d .
$$

New trees can be assigned to the developmental stage for which the corresponding discriminant function has the higher value.

\subsection{Selection of highly productive trees}

As indicated in Table $\mathrm{V}$, for each of the three productive development stages, trees were selected as plus trees. Ten trees (3.9\%) belonging to the cone production phase I, fifteen trees in $(10.4 \%)$ the cone production phase II and three (12\%) in the cone production phase III were identified as the trees with the highest productivity in terms of cone crop weight, the number of cones and relative productivity capacity.

\section{DISCUSSION}

According to Zobel and Talbert (1984), the selection of plus trees is the first step in the establishment of an improvement program. Productive stands of Pinus pinea are mostly unevenaged stands, so selection should be conducted, in all the provenance regions, on a wide range of trees. The age and the development stage of the tree should be taken into account. In Spain, Sierra (1987; cited in Gordo, 2004) proposed an approach for the selection of plus trees, that considered the diameter at breast height and the age of the tree, but the methodology has not been applied (Gordo, personal communication). Cañadas (2000; cited in Gordo, 2004) found that, in the same provenance region, cone production per tree was related to the size of the tree. In a stone pine grafted clone bank, Mutke et al. (2005a) found that $71 \%$ of cone yield was explained by tree size. Alpuim et al. (2000) also noted that, under similar ecological conditions, stone pine fructification depends mainly on the crown diameter. We used tree dimensions rather than age and our results show that cone production depends directly on the size of the tree, which is much easier to measure compared with tree age.

The present study is focused on developing a method for the selection of the best seed producers in Pinus pinea stands. To this end, groups of trees with similar dimensions and cone production had to be identified. This prompted us to use two multivariate approaches, cluster and discriminant analyses, to separate trees into different groups. These two methods have often been applied to pattern recognition (Akindele and LeMay, 2006; Finegan et al., 1999; Huang et al., 2007; Phillips et al., 2002; Schulz and Härtling, 2003). Based on six biometrical variables, five different developmental stages were defined. Discriminant analysis results showed that basal area, height diameter ratio and crown area are pertinent variables for classifying new trees. These variables express not only the size of the tree, but also effects of tree competition. Three out of the five development stages, cone production phase I (3), cone production phase II (4) and cone production phase III (5), were considered productive groups. These groups correspond to large trees $(d>40 \mathrm{~cm})$ growing in low density stands $(N T<110 /$ ha $)$.

Previous studies only used the number of cones for selection of plus trees. In this study, the number of cones and cone crop weight per tree were considered as complementary. These variables were assumed to be an indirect approach to the evaluation of kernel production, which is the ultimate goal. In fact, an equal number of cones in two different batches may have different weights. Carneiro (2005), relating cone and kernel production, estimated a genotypic correlation of 0.49 and 0.86 for cone weight with the number of seeds per cone and cone weight with the seed weight per cone, respectively. These correlations are connected to the long reproductive cycle of Pinus pinea L., which lasts for three years, beginning with pollination and ending with seed cone maturity. This cycle can be affected by biotic and/or abiotic factors. In most mature pines, a significant cause of reduced cone production is the abortion of cones after pollination due to low pollination success or the appearance of a frost after pollination (Owens and Fernando, 2007; Owens et al., 2008). Other factors can contribute to reduced seed production, such as incompatibility mechanisms or insect and disease damage at various stages of development (Owens, 2006). According to Mutke et al. (2005b), water stress during different cone development stages seems to be one of the most notable limiting factors for cone yield.

Long-term empirical evidence has shown that cone crop production follows a seven- to eight-year yield cycle. In our study, as cone production was monitored during three years, annual variations due to climatic conditions were considered reduced. In fact, we observed that throughout the three collecting seasons in each cluster, the most productive trees were approximately the same. This is indicative of the two productive stages, cone production phase II and cone production phase III, perhaps due to the progressive stability of tree cone production. Concerning cone production phase I, only $4 \%$ of the trees were selected, indicating that the productivity of this stage is not yet stable. To guarantee tree superiority, the trees should be evaluated during at least one production cycle. This allows the developmental classification stages to be used as a method of selecting candidates for plus trees inside the three productive groups.

This methodology for selecting trees assures the sustainability of the breeding program for this species. As a matter of fact, the enlargement of the base population with smaller trees (which are usually younger) increases genetic diversity, as 
Table V. Identification of the candidate plus trees and their cone production characterization variables: the number of cones $(n c)$, cone crop weight $(w c)$ and relative production capacity $(p c)$. The variables were obtained in the three years studied and in the three productive stages (Stage ID): cone production phase I (3), cone production phase II (4) and cone production phase III (5).

\begin{tabular}{|c|c|c|c|c|c|c|c|c|c|c|c|}
\hline Stage ID & Number of trees & $\begin{array}{c}\text { Tree } \\
\text { identification }\end{array}$ & $n c_{1}$ & $n c_{2}$ & $n c_{3}$ & $w c_{1}$ & $w c_{2}$ & $w c_{3}$ & $p c_{1}$ & $p c_{2}$ & $p c_{3}$ \\
\hline \multirow[t]{10}{*}{3} & 258 & 23_QS_7 & n.a. & 273 & 346 & n.a. & 66.3 & 115 & - & 0.42 & 0.73 \\
\hline & & 3_A_1 & n.a. & 266 & 143 & n.a. & 43.89 & 30 & - & 0.28 & 0.19 \\
\hline & & 21_CA $\mathrm{CA} C$ SC3 & n.a. & 215 & 326 & n.a. & 50.76 & 88 & - & 0.32 & 0.56 \\
\hline & & 1_CB_8 & n.a. & 190 & n.a. & n.a. & 43.85 & n.a. & - & 0.26 & - \\
\hline & & 5_M_2 & n.a. & 55 & 283 & n.a. & 18.39 & 106 & - & 0.12 & 0.71 \\
\hline & & 3_CB_10 & 697 & n.a. & 633 & 216 & n.a. & 170 & 1.11 & - & 0.87 \\
\hline & & 8_CB_5 & 483 & 294 & 58 & 187 & 65.53 & 20 & 0.83 & 0.29 & 0.09 \\
\hline & & 4_CB_11 & 431 & n.a. & 279 & 159 & n.a. & 83 & 0.98 & - & 0.51 \\
\hline & & $1 \overline{4} \_\mathrm{CB} \_7$ & 250 & 211 & 161 & 84 & 49.68 & 50 & 0.42 & 0.25 & 0.25 \\
\hline & & 6_QS_2 & 40 & 155 & 479 & 11 & 28.96 & 98 & 0.07 & 0.18 & 0.60 \\
\hline \multirow[t]{15}{*}{4} & 144 & 15_G_3 & n.a. & n.a. & 316 & n.a. & n.a. & 63 & - & - & 0.73 \\
\hline & & 12_G_4 & n.a. & n.a. & 173 & n.a. & n.a. & 41 & - & - & 0.40 \\
\hline & & 5_C̄ & n.a. & 216 & n.a. & n.a. & 48.15 & n.a. & - & 0.58 & - \\
\hline & & 19_MM_1 & n.a. & 203 & n.a. & n.a. & 30.21 & n.a. & - & 0.41 & - \\
\hline & & 3_PS_1 & n.a. & 196 & 152 & n.a. & 57.58 & 40 & - & 0.48 & 0.34 \\
\hline & & 7_A_2 & n.a. & 180 & n.a. & n.a. & 34.11 & n.a. & - & 0.31 & - \\
\hline & & 2_QS_2 & n.a. & 175 & 100 & n.a. & 27.78 & 19 & - & 0.37 & 0.25 \\
\hline & & 2_A_1 & n.a. & 102 & 185 & n.a. & 26.94 & 55 & - & 0.22 & 0.46 \\
\hline & & 15_M_2 & n.a. & 77 & 234 & n.a. & 21.77 & 69 & - & 0.24 & 0.77 \\
\hline & & 42_BS_2 & n.a. & 59 & 220 & n.a. & 12.05 & 63 & - & 0.17 & 0.90 \\
\hline & & 2_CB_10 & 510 & n.a. & 125 & 158 & n.a. & 33 & 1.17 & - & 0.24 \\
\hline & & 10_PS_2 & 403 & 150 & 148 & 134 & 31.03 & 47 & 0.94 & 0.22 & 0.33 \\
\hline & & 6_CB_1 & 330 & n.a. & 178 & 95 & n.a. & 41 & 1.07 & - & 0.46 \\
\hline & & 7_CB_9 & 303 & 275 & 61 & 79 & 37.15 & 10 & 0.91 & 0.43 & 0.12 \\
\hline & & 14_HE_43 & 79 & n.a. & 155 & 28 & n.a. & 47 & 0.25 & - & 0.42 \\
\hline \multirow[t]{3}{*}{5} & 25 & 15_CASC_3 & n.a. & 481 & 784 & n.a. & 109.96 & 226 & - & 0.29 & 0.61 \\
\hline & & 6_CB_10 & 1467 & n.a. & 890 & 364 & n.a. & 212 & 1.20 & - & 0.70 \\
\hline & & 1_QS_5 & 1120 & 342 & 139 & 391 & 60.89 & 33 & 1.15 & 0.18 & 0.10 \\
\hline
\end{tabular}

n.a.- not available.

stone pine improvement program strategies are mainly based on clonal propagation (Barreira and Alpuim, 1988; Gordo, 2004).

\section{CONCLUSIONS}

The aim of this study was to develop a methodology capable of identifying trees with high kernel production. In unevenaged stands, it is difficult to carry out an unbiased selection of plus trees for cone production without considering the development stage of the tree, as the most productive trees are likely the oldest. In this study, we proposed a classification of the stone pine tree developmental stages associated with tree dimensions and cone productivity. The five stage levels proposed are: juvenile (stage 1), dominant vegetative growth (stage 2), cone production phase I (stage 3), cone production phase II (stage 4) and cone production phase III (stage 5). The juvenile trees (for which selection is not possible) were gathered into stage 1 (juvenile) and stage 2 (dominant vegetative growth), which correspond to non-productive groups. The other three groups are considered to be productive stages.
Unclassified stone pine trees can be assigned to each developmental stage using the established discriminant functions. Plus trees should be selected among the three productive groups. Candidate trees must be evaluated yearly for their cone production for at least seven years. During this period, their individual annual cone production (determined by the number of cones and cone crop weight) should belong to the 90th quartile and their individual cone productivity should be among the highest within each development stage to qualify as plus trees.

Acknowledgements: This study was supported by the AGRO 451 project: "Stone Pine Stand Improvement and Management Optimization for Cone and Seed production". The authors would like to thank the forest owners for making cone material available.

\section{REFERENCES}

Alpuim M., Baeta J., Carneiro M.M., Carvalho M.A., Rocha M.E., and Pessoa, J., 2000. Classification of stone pine selected by pine kernels production, IUFRO International Meeting, Maio, Sevilha.

Akindele S.O. and LeMay V.M., 2006. Development of tree volume equations for common timber species in the tropical rain forest area of Nigeria. For. Ecol. Manage. 226: 41-48. 
Barreira and Alpuim, 1988. Contribuição para um programa de melhoramento de Pinheiro manso (Pinus pinea L.), Encontro sobre o Pinheiro manso organizado pela Sociedade Portuguesa de Ciências Florestais, de 25-26 de Novembro 1988 em Alcácer do Sal.

Cardoso M.M. and Lobo P.A., 2001. Delimitação de pisos bioclimáticos e regiões de proveniência de Pinheiro manso em Portugal, usando sistemas de informação geográfica, Silva Lusitana 9: 93-108.

Carneiro A.N., 2005. Ganhos genéticos na selecção de características biométricas das pinhas e semente de Pinheiro manso, V Congresso Florestal Nacional, organizado pela Sociedade Portuguesa de Ciências Florestais, 16-19 de Maio 2005 em Viseu.

DGRF, 2006. Resultados Preliminares do Inventário Florestal Nacional 2005-2006, Apresentação realizada na Torre do Tombo, em Março 2008, Direcção Geral dos Recursos Florestais, Lisboa.

Finegan B., Camacho M., and Zamora N., 1999. Diameter increment patterns among 106 tree species in a logged and silviculturally treated Costa Rica rain forest. For. Ecol. Manage. 121: 159-176.

Gordo F.J., 2004. Selección de grandes productores de fruto de Pinus pinea L. en la Meseta Norte, Tesis Doctoral, Escuela Técnica Superior de Ingenieros de Montes, Universidad Politécnica de Madrid.

Huang J.Y., Guo X.P., Qiu Y.B., and Chen Z.Y., 2007. Cluster and discriminant analysis of electrochemical noise dta. Electrochimica, Acta 53: 680-687.

Huberty C.J., 1994. Applied Discrinimant Analysis, John Wiley \& Sons, Inc., New York, 466 p.
Mutke S., Gordo J., and Gil L., 2005a. Cone yield characterization of a stone pine (Pinus pinea L.) clone bank. Silvae Genet. 54: 189-197.

Mutke S., Gordo J., and Gil L., 2005b. Variability of Mediterranean stone pine cone production: yield loss as response to climate change. Agric. For. Meteorol. 132: 263-272.

Owens J.N., 2006. The reproductive biology of lodgepole pine, FGC extension note 07, ISBN: 0-7726-5342-9, 62 p.

Owens J.N. and Fernando D.D., 2007. Pollination and seed production on western white pine (Pinus albicaulis Engelm.) seed production in natural stands. Can. J. For. Res. 37: 260-275.

Owens J.N., Kittirat T., and Malalovich M.F., 2008. Whitebark pine (Pinus albicaulis Engelm.) seed production in natural stands. For. Ecol. Manage. 255: 803-809.

Phillips P.D., Yasman I., Brash T.E., and van Gardingen P.R., 2002. Grouping tree species for analysis of forest data in Kalimantan (Indonesian Borneo). For. Ecol. Manage. 157: 205-216.

SAS Institute Inc., 1999. SAS/STAT ${ }^{\circledR}$ User's Guide, Version 8, Cary $\mathrm{NC}, 3884 \mathrm{p}$.

Schulz H. and Härtling S., 2003. Vitality analysis of Scots pines using a multivariate approach. For. Ecol. Manage. 186: 73-84.

Thompson M.E., 1999. The Science and Art of Market Segmentation Using PROC FASTCLUS, Proceedings of the 24th Annual Conference SAS User's Group International, 11-14 April, Miami Beach, Florida, No. 270.

Zobel B. and Talbert J., 1984. Applied forest tree improvement, John Wiley \& Sons, New York, 505 p. 